\title{
Nutraceutical intervention with colostrum replacer: Can we reduce disease hazard, ameliorate disease severity, and improve performance in preweaned dairy calves?
}

\author{
M. C. Cantor, ${ }^{1} \odot$ D. L. Renaud, ${ }^{2} \odot$ and J. H. C. Costa ${ }^{1 *} \oplus$ \\ ${ }^{1}$ Dairy Science Program, Department of Animal and Food Sciences, University of Kentucky, Lexington 40546 \\ 2Department of Population Medicine, University of Guelph, Guelph, Ontario, N1G 2W1, Canada
}

\begin{abstract}
The objective of this randomized clinical trial was to determine if an intervention with colostrum replacer (CR; Premolac Plus, Zinpro; $125 \mathrm{~g} / \mathrm{d}$ fed for $3 \mathrm{~d}$ ) or a placebo milk replacer (Cows Match, Land O'Lakes Inc.; $125 \mathrm{~g} / \mathrm{d}$ for $3 \mathrm{~d}$ ) following a triggered alarm could ameliorate disease bouts in dairy calves. The alarm was set to detect negative deviations of milk intake $(20 \%$ reduction) or drinking speed (30\% reduction) in relation to a calf's 12-d rolling average feeding behavior. Calves were enrolled on this study $(\mathrm{n}=42 \mathrm{CR}, \mathrm{n}=$ 42 placebo) when they triggered an alarm from d 14 to 50 on the feeder before weaning. Once calves were enrolled, calves received a bottle of either $125 \mathrm{~g}$ of CR or milk replacer mixed with $1 \mathrm{~L}$ of water for $3 \mathrm{~d}$. Calves were enrolled on the automated milk feeder at age 4.0 $\pm 2.0 \mathrm{~d}($ mean $\pm \mathrm{SD})$, were offered $10 \mathrm{~L} / \mathrm{d}$ of the same milk replacer fed as a placebo, and had ad libitum access to calf starter measured by automated feeders. Weaning began at d 50, with $50 \%$ reduction of milk replacer across $14 \mathrm{~d}$, and an additional $20 \%$ reduction for another $7 \mathrm{~d}$ before weaning at $\mathrm{d} 70$. Calves were health scored from birth to 2 wk postweaning ( $88 \pm$ $2.0 \mathrm{~d}$ of age) daily for bovine respiratory disease (BRD) and diarrhea, and were weighed and scored using lung ultrasonography twice weekly. A BRD score $\geq 5$ and an area of consolidated lung $\geq 3.0 \mathrm{~cm}^{2}$ was considered BRD positive; diarrhea was defined as a watery fecal consistency that sifted through the bedding. The effect of $\mathrm{CR}$ on BRD and diarrhea likelihood were calculated with logistic models; the $7 \mathrm{~d}$ before and after an alarm were fixed effects, with milk intake as a covariate. A Cox proportional hazards model evaluated the effect of $\mathrm{CR}$ on the hazard of being positive for BRD and diarrhea following enrollment, with sex as a fixed effect in the diarrhea model. The effect of $\mathrm{CR}$ on average daily
\end{abstract}

Received September 16, 2020.

Accepted January 29, 2021.

*Corresponding author: costa@uky.edu gain the week following intervention was evaluated with linear modeling with repeated measures, and birth date was a random effect. After intervention, placebo calves had 1.64 (95\% CI: 1.11-2.43) times greater odds of having a BRD bout compared with CR calves for the 7 d following intervention. Moreover, placebo calves had 1.50 (95\% CI: 1.11-2.08) times greater odds of having lobar lung consolidation in the $7 \mathrm{~d}$ after intervention than CR calves. No difference was found in the likelihood of diarrhea in the $7 \mathrm{~d}$ after intervention (odds ratio: $0.91 ; 95 \%$ CI: 0.71-1.16). However, placebo calves had a 2.38 (95\% CI: 1.30-4.33) times greater hazard of incurring BRD in the $14 \mathrm{~d}$ after intervention. Average daily gain was not associated with an intervention with CR for the $7 \mathrm{~d}$ after intervention (placebo: $0.73 \pm$ $0.07 \mathrm{~kg} / \mathrm{d}$; CR: $0.70 \pm 0.08 \mathrm{~kg} / \mathrm{d} ; \mathrm{LSM} \pm \mathrm{SEM})$. These results suggest CR may reduce BRD likelihood but did not influence growth in calves offered high allowances of milk. Future research should examine which properties of $\mathrm{CR}$ ameliorate $\mathrm{BRD}$ in calves.

Key words: bovine respiratory disease, diarrhea, growth, preweaning, supplement

\section{INTRODUCTION}

Bovine respiratory disease complex (BRD) and diarrhea are significant causes of morbidity in dairy calf operations, and disease mitigation may increase farm efficiency. According to a national producer survey, BRD and diarrhea affected $33 \%$ of preweaned dairy calves, with a high majority of affected calves receiving antibiotics (BRD 95\% and diarrhea 76\%; USDA 2018). It is essential to mitigate disease as the preweaning period is the most economically intensive for heifer raising operations (Hawkins et al., 2019). For example, BRD was estimated to cost $\$ 42 /$ calf (Dubrovsky et al., 2020) and treatment for diarrhea was estimated to cost a median of $\$ 56 /$ calf (Goodell et al., 2012). Furthermore, in the short term BRD (i.e., lung consolidation on ultrasound) was associated with lower preweaning ADG (Cramer and Ollivett, 2019). In the long term, BRD 
at weaning was associated with lower milk production during the first lactation (Dunn et al., 2018) and a lower hazard of pregnancy, coupled with a lower hazard of producing milk in the first lactation (Teixeira et al., 2017). Similarly, diarrhea identified preweaning was associated with a lower hazard of pregnancy (Aghakeshmiri et al., 2017). Therefore, it is of interest to mitigate incidence of BRD and diarrhea. Moreover, lowering the duration of disease will improve calf welfare because disease is metabolically costly and potentially painful for calves.

The dairy industry is under pressure to lower reliance on antibiotics, particularly for subtherapeutic use (as reviewed by Placzek et al., 2020); thus, alternative therapies should be considered for mitigating disease risk in calves. One potential alternative therapy is the use of nutraceuticals, which are nutritional interventions thought to have positive effects on physiological status and health outcomes (as reviewed by Nasri et al., 2014). For example, colostrum may be a nutraceutical intervention for calves, as it has a high immunoglobulin and lactoferrin content (Giansanti et al., 2016) and anti-inflammatory properties (Lee et al., 2019). Interestingly, first-milking bovine colostrum has been used as a preventative nutraceutical to ameliorate disease in human medicine and is considered a common practice (as reviewed by Alexieva et al., 2011, and Bagwe et al., 2015). Similar immune improvement has been observed in parallel in other species: immunocompromised mice (Menchetti et al., 2020), weaned piglets (Boudry et al., 2007), and dogs vaccinated for distemper (Satyaraj et al., 2013). Moreover, 100 young Thoroughbred horses fed a colostrum nutraceutical at $(50 \mathrm{~g} / \mathrm{d})$ for $4 \mathrm{mo}$ ameliorated disease duration (2 wk) versus soy flour controls (4 wk: Fenger et al., 2016). Thus, bovine colostrum as a nutraceutical may improve immune status in other species. To date, there is no work that has investigated the efficacy of colostrum nutraceuticals as an intervention strategy for dairy calves at risk for disease. However, there is literature that suggests feeding colostrum to healthy dairy calves as a longer-term preventative feeding strategy may improve calf health outcomes.

There is preliminary evidence that healthy dairy calves benefit from the preventative feeding, or extended feeding, of colostrum as a nutraceutical. For example, calves fed colostrum replacer $(150 \mathrm{~g} / \mathrm{d})$ during the first $14 \mathrm{~d}$ of life had lower odds of abnormal feces or abnormal respiration, and decreased odds of receiving antibiotics (Chamorro et al., 2017). Different results were observed at a lower dosage, where 30 calves receiving a colostrum nutraceutical at $70 \mathrm{~g} / \mathrm{d}$ had a lower likelihood of diarrhea, and a decreased likelihood of receiving antibiotics, but the odds of developing
BRD were not different (Berge et al., 2009). Moreover, a recent study observed that partially replacing the milk diet with different levels of colostrum at up to $700 \mathrm{~g} / \mathrm{d}$ reduced the odds of diarrhea, improved performance, and tended to reduce the risk of BRD (Kargar et al., 2020). Similarly, there is evidence that extended colostrum feeding for the first $21 \mathrm{~d}$ of life decreased BRD morbidity for the first year of life and decreased diarrhea risk, whereas milk production was higher for extended colostrum-fed calves during the first lactation (Armengol and Fraile, 2020). Hence, there is the potential for colostrum to ameliorate disease in dairy calves when fed as a preventative therapy. However, it is unknown if colostrum can be used as an intervention feeding strategy to mitigate disease risk in calves.

One limitation to feeding a colostrum nutraceutical across an extended period is cost. Therefore, it is of interest to determine if an intervention provided to a calf during early signs of disease development can lower disease likelihood and ameliorate disease bouts. Automated milk feeding systems, which measure and record feeding behavior of dairy calves, are able to detect deviations in feeding behavior that have been associated with disease development (Knauer et al., 2017; Sutherland et al., 2018). Therefore, the objective of this study was to determine if intervention with one dose of a colostrum replacer $(\mathbf{C R})$ nutraceutical fed across $3 \mathrm{~d}$ (125 g of CR mixed with $1 \mathrm{~L}$ of water by bottle) versus a control milk replacer $(125 \mathrm{~g}$ mixed with $1 \mathrm{~L}$ of water by bottle), offered to calves that triggered an automated feeder alarm detected by the default automated feeder algorithm could ameliorate disease bouts (BRD and diarrhea), reduce the odds of disease, and improve performance $(\mathrm{ADG})$ in calves offered intermediate levels of milk $(10 \mathrm{~L} / \mathrm{d})$ for $50 \mathrm{~d}$. We chose deviations in feeding behavior as an intervention point because an epidemiological study found an association between negative deviations in feeding behavior up to $4 \mathrm{~d}$ before disease in calves fed by automated feeders (Knauer et al., 2017). We hypothesized that CR would ameliorate disease bouts (BRD and diarrhea), and reduce the odds of disease in calves, but would not affect performance.

\section{MATERIALS AND METHODS}

This study was conducted at the University of Kentucky Coldstream Research Dairy Farm in Lexington, KY from July 2018 to August 2019. This facility was selected for the availability of dairy calves with a high prevalence of passive transfer in the herd (90\%), and due to the ability to blind farm staff to treatment assignments for this study. A total of 120 calves were selected for this trial, of which 84 calves (placebo = $42 ; \mathrm{CR}=42$ ) met the following enrollment criteria: 
removed from dam within $6 \mathrm{~h}$ and fed maternal colostrum, had a serum BRIX of $8.4 \%$ at $48 \mathrm{~h}$ of life as a passive transfer threshold (Deelen et al., 2014), were not a twin, and triggered an alarm on the automated milk feeder between feeder d 14 to 50 . All calves enrolled were part of the Institutional Animal Care and Use Committee approval number 2018: 2864.

\section{Management and Feeding}

Calves were randomly assigned (www.random.org) by due date in groups of 10 to receive an intervention with either 1 dose (375 g, given as $125 \mathrm{~g} / \mathrm{d}$ for $3 \mathrm{~d}$ ) containing $150 \mathrm{~g}$ of IgG CR (Premolac Plus, Zinpro; \% DM basis minimum $70 \% \mathrm{CP}$, and maximum $8 \%$ fat, $0.2 \%$ crude fiber, $10 \%$ ash, and contained 4.65 Mcal of ME/kg) or placebo milk replacer (Cows Match, Land O'Lakes Inc.). Milk replacer on a percentage DM basis was a minimum $28 \% \mathrm{CP}, 20 \%$ fat, a maximum $15 \%$ crude fiber, a minimum $1.0 \%$ calcium and $0.70 \%$ phosphorus, and contained $4.87 \mathrm{Mcal}$ of $\mathrm{ME} / \mathrm{kg}$. The treatment dose was fed at $1100 \mathrm{~h}$ by bottle to calves that received an alarm that morning detected by an automated milk feeder (AMF; Forster-Technik); the 2 researchers were not blind to treatment, as the bottles needed to be prepared across $3 \mathrm{~d}$ ( $125 \mathrm{~g} / \mathrm{d}$ in $1 \mathrm{~L}$ of water). Similarly, the calves received the placebo dose of milk replacer by bottle for $3 \mathrm{~d}$ ( $125 \mathrm{~g} / \mathrm{d}$ in $1 \mathrm{~L}$ of water).

No study has investigated the ability of a colostrum intervention to reduce BRD incidence in calves. Thus, we powered this study based on true herd BRD incidence $(60 \%)$ calculated before the study with a $10 \%$ reduction in disease; we considered $10 \%$ to be the minimum disease reduction required for colostrum to be considered as a potential nutraceutical intervention. A power analysis showed that a total of 84 calves $(\mathrm{n}=$ 42 per treatment) was required at $80 \%$ power to detect a $10 \% \mathrm{BRD}$ incidence difference, with half-widths at 0.05 , and true herd BRD incidence at $60 \%$. Our power analysis for ADG showed that a total of 62 calves (n $=31$ per treatment) were required for calves offered 10 $\mathrm{L} / \mathrm{d}$ in an AMF at an average ADG $0.67 \mathrm{~kg} / \mathrm{d}$, with a variation of $0.07 \mathrm{~kg} / \mathrm{d}$, as was observed in the literature (Rosenberger et al., 2017). The power analysis for ADG projected a targeted difference of $0.05 \mathrm{~kg} / \mathrm{d}$ between treatments in ADG for feeding CR at 80\% power, and half-widths at 0.05. The true herd incidence for BRD was calculated by one trained researcher health scoring all newborn calves from birth until 2 wk postweaning twice weekly for 9 mo using the UW Calf Health Scoring System to define a new BRD case (48/80 BRD calves; McGuirk and Peek, 2014) before this study. The AMF algorithm that was used was the default manufacturer alarm programmed into the automated calf feeder. The AMF algorithm generated a baseline feeding behavior average for milk intake, and for drinking speed, based on the rolling $12 \mathrm{~d}$ average for each calf. The AMF triggered an alarm when a calf deviated in milk intake (20\% reduction) or drinking speed (30\% reduction) from this rolling baseline average. Calves could trigger an AMF alarm from feeder d 14 to 50 .

Calves were removed from the dam within $6 \mathrm{~h}$ after birth and placed in individual pens $(3 \times 3 \mathrm{~m})$ bedded with sawdust and were weighed using an electronic scale (Brecknell PS1000, Avery Weigh-Tronix LLC) weighing $40.08 \pm 5.46 \mathrm{~kg}($ mean $\pm \mathrm{SD})$ at birth. Calves were fed $6 \mathrm{~L} / \mathrm{d}$ of $840 \mathrm{~g}$ milk replacer (Cow's Match; Land O'Lakes Animal Milk Products Co.) by bottle, divided into 2 feedings when housed individually. Calves were enrolled on the AMF when a strong suckle reflex was present at an average age of $4.0 \pm 2.0 \mathrm{~d}$ and placed in a group pen $(4.57 \times 10.67 \mathrm{~m})$ containing $6 \pm 3$ other calves and bedded with sawdust shavings. Pens were cleaned, emptied, and bedding was removed and sanitized every $2 \mathrm{wk}$. To ensure calves in a pen were of similar size and age, calves were moved to an identical adjacent pen with the same stocking density using dynamic flow at an average age of $45.0 \pm 3.0 \mathrm{~d}$ before weaning.

Calves were fed the first meal with human assistance on the AMF and received human assistance every 12 $\mathrm{h}$ (maximum learning duration 4 feedings) until independent milk consumption was observed. Calves were allotted up to $10 \mathrm{~L}(140 \mathrm{~g} / \mathrm{L})$ of milk replacer per day from the AMF (Cow's Match; Land O'Lakes Animal Milk Products Co.) for 50 d. A step-down gradual weaning procedure was performed at d 51 where milk allowance was reduced to $50 \%$ allotment for $14 \mathrm{~d}$, and then reduced to $20 \%$ allotment for an additional $7 \mathrm{~d}$ until complete weaning at $70 \mathrm{~d}$. Calves were followed for $14 \mathrm{~d}$ postweaning.

The automated calf starter feeder contained a $22 \%$ CP calf starter feed (Calf Starter; Baghdad Feeds). Calves were also offered chopped alfalfa hay in a trough $(1.83 \times 0.33 \times 0.16 \mathrm{~m})$. Both the AMF and the calf starter feeder were calibrated weekly according to manufacturer instructions. All calves had ad libitum access to water, calf starter, and chopped alfalfa hay during the study period.

\section{Health Exams}

Calves were scored daily beginning at birth to $2 \mathrm{wk}$ postweaning at $88 \pm 2.0 \mathrm{~d}$ of age by 1 of 3 observers (interobserver agreement $\kappa>0.90$ ) for BRD using the UW Calf Health Chart (McGuirk and Peek, 2014), 
which assigns and sums the nasal discharge score, eye discharge score, ear tilt score, cough score, and temperature score. Moreover, calves were rectally stimulated daily for fecal consistency assessment (interobserver agreement $\kappa>0.95$ ). Calf fecal consistency scoring scale was: 1 soft (does not hold form, piles but spreads slightly), 2 runny (spreads readily), and 3 watery (liquid consistency, splatters), a score of 3 was considered diarrhea (Renaud et al., 2020).

The interobserver agreement for health scoring was measured using Fleiss' kappa every 4 mo throughout the study by having all observers go to a commercial facility on the same day to score 40 calves where the health status of the calves was unknown to ensure unbiased agreement. Similarly, 12 calves enrolled on a separate study and kept in a separate pen at this facility (Woodrum Setser et al., 2020) were evaluated for interobserver agreement for health scoring twice. Similarly, the calves from (Woodrum Setser et al., 2020) were scored using lung ultrasonography by 2 observers on one morning, and euthanized that afternoon (euthanasia was part of the study protocol); the lungs were retrieved and scored by a researcher blind to the researcher's scores to confirm that the 2 observers diagnosed lung lobe status accurately (interobserver agreement Cohen's kappa; $\kappa$ $=0.90)$.

Weights were collected twice weekly using the same scale used to weigh calves at birth. Lung ultrasounds were collected twice weekly using $70 \%$ isopropyl alcohol as a transducing agent and by evaluating 5 lung lobes in each calf with 1 of 2 observers (interobserver agreement Cohen's kappa; $\kappa=0.90$ ) with a portable linear rectal ultrasound (Buczinski et al., 2018). In brief the ultrasound was set to a depth of $9 \mathrm{~cm}$, frequency of 6.2 $\mathrm{MHz}$, and gain of $23 \mathrm{~dB}$ (near $13 \mathrm{~dB}$; far $36 \mathrm{~dB}$; Ibex Pro, E.I. Medical). A BRD score $\geq 5$ and lobar consolidation in any one lung lobe $\geq 3.0 \mathrm{~cm}^{2}$ was considered a BRD bout, as described in (Buczinski et al., 2018). All calves with a positive BRD bout received enrofloxacin subcutaneously with dosage calculated by BW (Baytril, Bayer; $1 \mathrm{~mL} / 15 \mathrm{~kg}$ ) according to the herd veterinarian protocol. Calves who failed to respond to BRD bout antibiotic treatment were not retreated until $14 \mathrm{~d}$ after the first treatment. Calves who failed to repond to antibiotic treatment were classified as a new BRD bout on d 15 if calves had an average BRD score $\geq 5$ from d 10 to 14 after antibiotic treatment and at least one lung lobe consolidation at $\geq 3.0 \mathrm{~cm}^{2}$. Failure-to-respond calves were treated with tulathromycin (Draxxin, Zoetis Animal Health; $1 \mathrm{~mL} / 45 \mathrm{~kg}$, once at diagnosis, subcutaneously). Every health exam also included palpation of the umbilical site and was graded as a score of zero (closed), 1 (open, normal), or 2 (swelling, clouded discharge infection; following Cantor et al., 2019). Only one calf presented with an umbilical infection and was eliminated from this study and not enrolled.

\section{Statistical Analysis}

All statistical methods were carried out in SAS version 9.4 (SAS Institiute). Initially, descriptive statistics and residual diagnostics assessed the relationship with all outcomes reported at the univariable level, using a cutoff of $P<0.20$ for inclusion in the model. Normality was confirmed by visual assessment of residuals in the model using quartile plots.

The $t$-tests (Proc Ttest) were used to confirm there was no difference between treatments for health status, weight, and feeding intake (milk and calf starter) on the day before triggering the alarm, and differences in feed intake in the week after the alarm were also assessed.

Efficacy of CR on Ameliorating Disease. The effect of CR to ameliorate a BRD bout was calculated with a logistic model (PROC Logistic) utilizing the 7 d before and after an alarm as fixed effects, with milk intake as a covariate. The effect of CR to ameliorate a diarrhea bout was calculated with a logistic model (PROC Logistic) utilizing the $7 \mathrm{~d}$ before and after an alarm as fixed effects, with milk intake as a covariate.

Effect of CR on Survival from a Disease Bout. A survival analysis using Breslow methods (PROC Lifetest) was performed to determine if treatment intervention affected the hazard of being positive for a BRD bout in the $14 \mathrm{~d}$ following treatment. Calves were classified as healthy at $15 \mathrm{~d}$ if they were never diagnosed with a BRD bout. A survival analysis using Breslow methods was also performed to determine if treatment intervention affected the hazard of being positive for a diarrhea bout in the $14 \mathrm{~d}$ following treatment. Calves were classified healthy at $15 \mathrm{~d}$ if they were never diagnosed with a diarrhea bout.

Effect of CR on Odds of a Disease Bout. A Cox proportional hazards model (PROC Hazard) evaluated the effect of CR on the hazard of a BRD bout using the Nelson-Aalen cumulative hazard method. Nelsen-Aalen cumulative hazards were used because the probability of survival from a disease bout generated in these calves was for a short duration of $14 \mathrm{~d}$. A Cox proportional hazards model also evaluated the effect of $\mathrm{CR}$ on the hazard of a diarrhea bout with sex as a fixed effect using the Nelson-Aalen cumulative hazard method. In the Cox proportional hazards model, proportionality assumption was tested graphically using log-log plots. No outliers were found in any of the models.

Effect of $C R$ on Improving Performance. The effect of CR on the ADG during the $7 \mathrm{~d}$ after the in- 
tervention was determined using a mixed linear model (PROC Mixed) with dam parity, feed intake, and BRD status as covariates, repeated by day, calf as a subject, and birth date as a random effect. Sex was evaluated for its association with ADG, but it was not significant and was removed from the model. The effect of CR on $\mathrm{ADG}$ for the 2 wk postweaning was also evaluated with a mixed linear model, with BRD status and calf starter intake as covariates, repeated by day and calf. To ensure outliers did not have leverage, standardized residuals were plotted against predicted outcomes to assess for model leverage, though no extreme outliers were identified.

\section{RESULTS}

\section{Descriptive Statistics}

A total of 120 calves were followed, but 2 calves did not meet enrollment criteria (failed transfer of passive immunity), 1 calf had an umbilical infection before enrollment, and 27 calves never triggered an alarm from d 14 to 50 . There were 6 calves ( 3 placebo and $3 \mathrm{CR}$ ) that refused the bottle on one of the $3 \mathrm{~d}$ of intervention, and thus, these 6 calves were not enrolled in the analysis due to failure to complete the treatment. A total of 84 calves with 14 bulls and 28 heifers per treatment (CR $=42$; placebo $=42)$ triggered an alarm from the $\mathrm{AMF}$ (112 alarms), drank the offered treatment on all $3 \mathrm{~d}$, and were assigned to a treatment group $(\mathrm{n}=59$ alarms to placebo, $\mathrm{n}=53$ alarms to $\mathrm{CR}$ ). Only the first alarm for each calf was considered for all health outcomes (42 placebo and $42 \mathrm{CR}$ calves). Treatment groups did not differ on the day before alarm for health status (BRD: 4 placebo, $3 \mathrm{CR}$; diarrhea: 14 placebo, $13 \mathrm{CR}$ ), or BW [placebo: $56.34 \pm 2.31 \mathrm{~kg}$; CR: $57.19 \pm 2.20 \mathrm{~kg}$ (mean $\pm \mathrm{SE}) ; P>0.10]$. Similarly, health status was not different on the day the alarm was triggered, and no new cases of BRD or diarrhea were present. Calf age was also not different on the day the alarm was triggered (placebo: $31.63 \pm 1.67 \mathrm{~d}$; CR: $32.51 \pm 1.67$ d; $P>0.10)$. Similarly, average milk intake on the day before the alarm was not different between treatments (placebo: $7.91 \pm 0.23 \mathrm{~L}$; CR: $7.87 \pm 0.29 \mathrm{~L} ; P>0.10$ ). Calf starter intake was also not different between treatments on the day before the alarm (placebo: $0.15 \pm$ $0.06 \mathrm{~kg} ; \mathrm{CR}: 0.18 \pm 0.04 ; P>0.10)$.

For the week after treatment intervention, milk intake was not different between treatments (placebo: $8.17 \pm$ $0.11 \mathrm{~L} / \mathrm{d}$; CR: $8.18 \pm 0.10 \mathrm{~L} ; P>0.10$ ) but calf starter intake was greater for $\mathrm{CR}$ calves (placebo: $0.16 \pm 0.02$ $\mathrm{kg} / \mathrm{d} ; \mathrm{CR}: 0.28 \pm 0.02 \mathrm{~kg} / \mathrm{d} ; P<0.001)$. Similarly, calf starter intake postweaning was different between treatments (placebo: $3.52 \pm 0.09 \mathrm{~kg} / \mathrm{d}$; CR: $4.08 \pm 0.10$ $\mathrm{kg} / \mathrm{d} ; P<0.001)$.

\section{Efficacy of CR on Ameliorating Disease}

Calves in the placebo group had 1.64 (95\% CI: 1.112.43; $P=0.01)$ times greater odds of being positive for BRD compared with CR calves for the $7 \mathrm{~d}$ following intervention (18 placebo calves vs. $11 \mathrm{CR}$ calves). Moreover, placebo calves had a 1.50 (95\% CI: 1.15-2.08; $P=$ $0.01)$ times greater odds of having lobar lung consolidation than CR calves for the $7 \mathrm{~d}$ following intervention (21 placebo calves vs. $14 \mathrm{CR}$ calves). No difference was found in the likelihood of diarrhea between groups for the $7 \mathrm{~d}$ following treatment intervention (OR 0.91; $95 \%$ CI: $0.71-1.16 ; P>0.10 ; 11$ placebo calves and $12 \mathrm{CR}$ calves).

\section{Effect of CR on Disease Bout: Survival}

BRD Complex. A BRD bout was defined as a calf developing at least lobar lung consolidation $\geq 3.0 \mathrm{~cm}^{2}$ and a BRD score of $\geq 5$. Placebo calves had 2.38 times (95\% CI: 1.30-4.33) higher hazard of incurring a BRD bout in the $14 \mathrm{~d}$ after intervention compared with CR calves $(P=0.001)$. Treatment intervention evaluated by Breslow survival curves for the $14 \mathrm{~d}$ after treatment were significantly different (Figure $1 ; P=0.001$ ). For example, the first quartile (25\%) of placebo calves were already positive for BRD by d 3 (95\% CI: $1-5)$, and placebo calves were positive for BRD on average at 7.50 $\pm 0.82 \mathrm{~d}$ (mean $\pm \mathrm{SE}$ ) after treatment. In contrast, the first quartile of CR calves was positive for BRD later at d 7 (95\% CI: 5-8) and CR calves were positive for BRD on average at $10.51 \pm 0.63 \mathrm{~d}$ after treatment. Moreover, a placebo calf's Nelson-Aalen cumulative hazard of having BRD by d 14 was $1.09 \pm 0.22( \pm \mathrm{SE})$, and the Breslow survival probability of remaining healthy on d 13 was 0.33. Alternatively, a CR calf's Nelson-Aalen cumulative hazard of having BRD by d 13 was $0.50 \pm$ 0.12 , and the Breslow survival probability of remaining healthy was 0.60 . The proportion of calves who were positive for BRD in the $14 \mathrm{~d}$ after intervention is summarized in Table 1.

Diarrhea. The hazard of incurring diarrhea in the $14 \mathrm{~d}$ postintervention was not different by treatment intervention $(P=0.18)$. Similarly, the treatment intervention survival curves for the after treatment intervention had overlapping Hall-Welner confidence interval bands and were not significantly different (Figure 2; $P$ $=0.16)$. For example, the first quartile of calves was positive for diarrhea by d 3 for placebo (95\% CI: $2-5$ ), and d 4 for CR (95\%: CI 3-7). Nearly all calves had a 


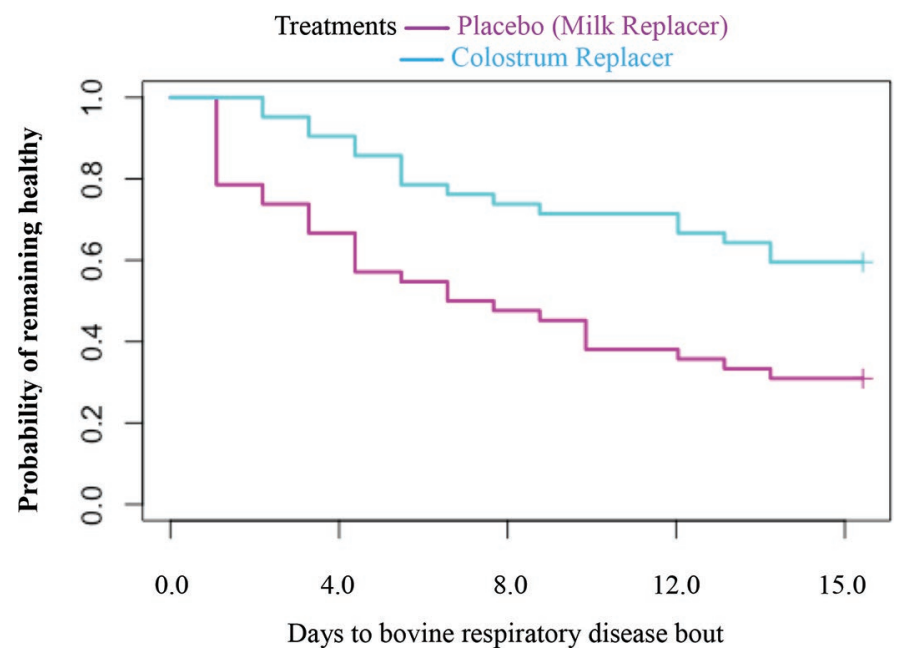

Figure 1. Breslow survival probability estimates $(P<0.01)$ with number of subjects ( $\mathrm{n}=84 ; 42$ colostrum replacer, 42 placebo) at risk for a bovine respiratory disease bout. Day 0 represents when an automated feeder alarm (negative deviation in baseline milk intake or drinking speed) was detected for a calf. All calves received $125 \mathrm{~g}$ of either milk replacer (placebo) or colostrum replacer in $1 \mathrm{~L}$ of water for 3 d. Day 15 represents calves that remained healthy.

diarrhea event (Table 2); the Nelson-Aalen cumulative hazard of a diarrhea bout by d 9 was placebo $0.84 \pm$ $0.18( \pm \mathrm{SE})$, and CR $0.70 \pm 0.15$.

\section{Effect of CR on Improving Performance}

The final weight of calves 2 wk postweaning was $104.1 \pm 18.17 \mathrm{~kg}$ (mean $\pm \mathrm{SD})$ for placebo and $104.3 \pm$ $18.78 \mathrm{~kg}$ for CR. Average daily gain was not affected by treatment intervention for the $7 \mathrm{~d}$ following intervention (placebo $0.73 \pm 0.07 \mathrm{~kg} / \mathrm{d}$ and $\mathrm{CR} 0.70 \pm 0.08$ $\mathrm{kg} / \mathrm{d} ; P>0.10$; LSM $\pm \mathrm{SEM})$. The ADG for calves from birth to $90 \mathrm{~d}$ of age (2 wk postweaning) was also not different by treatment (placebo $1.12 \pm 0.11 \mathrm{~kg} / \mathrm{d}$ and CR $0.96 \pm 0.11 \mathrm{~kg} / \mathrm{d} ; P>0.10)$. Similarly, ADG was not associated with treatment intervention for the 2 wk postweaning (placebo $1.26 \pm 0.08 \mathrm{~kg} / \mathrm{d}$ and CR $1.17 \pm 0.08 \mathrm{~kg} / \mathrm{d} ; P>0.10)$.

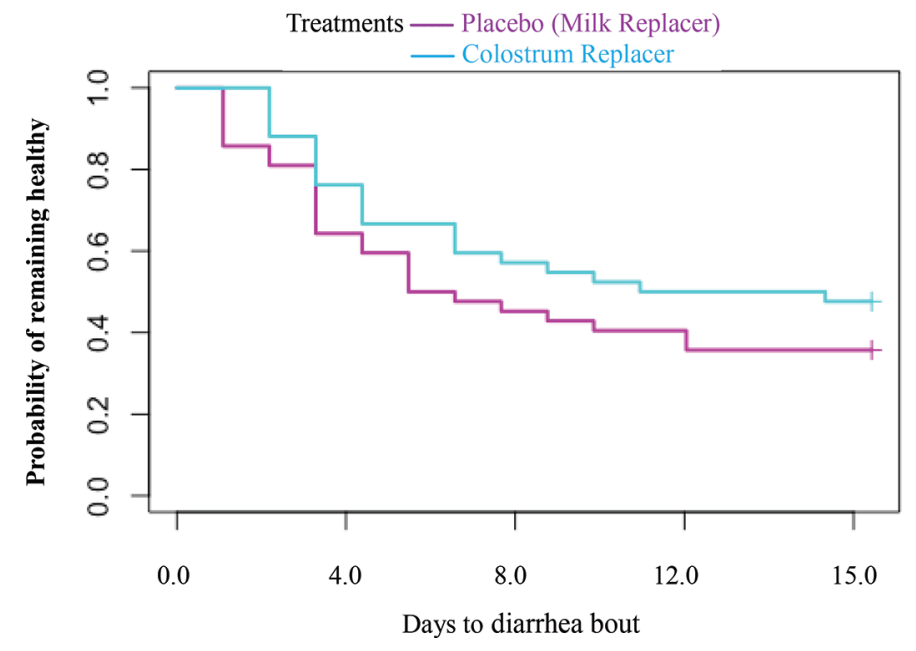

Figure 2. Breslow survival probability estimates $(P<0.01)$ with number of subjects $(\mathrm{n}=84 ; 42$ colostrum replacer, 42 placebo) at risk for a diarrhea bout. Day 0 represents when an automated feeder alarm (negative deviation in baseline milk intake or drinking speed) was detected for a calf. All calves received $125 \mathrm{~g}$ of either milk replacer (placebo) or colostrum replacer in $1 \mathrm{~L}$ of water for $3 \mathrm{~d}$. Day 15 represents calves that remained healthy.

\section{DISCUSSION}

The objective of this study was to determine if we could ameliorate BRD or diarrhea bouts, reduce the odds of these diseases, and improve performance by feeding a CR intervention to preweaned calves who triggered a feeding behavior alarm. We found that CR may serve as a nutraceutical for preweaned calves, as it reduced the hazard of a BRD bout, and increased the probability of remaining healthy $15 \mathrm{~d}$ after intervention. However, we did not observe any effect of CR intervention on ameliorating diarrhea or improving performance. To our knowledge, this is the first study to evaluate the effect of early intervention of a CR nutraceutical in response to a change in a feeding behavior alarm. Early intervention with CR may improve calf welfare as BRD is one of the leading causes of mortality in preweaned calves (Dubrovsky et al., 2019). Similarly, $\mathrm{BRD}$ is economically costly to treat (Dubrovsky et al.,

Table 1. Proportion of preweaned group-housed calves $(\mathrm{n}=84)$ with a bovine respiratory disease (BRD) bout $14 \mathrm{~d}$ following treatment after triggering a health alarm on automated feed system for negative deviations in milk intake or drinking speed ${ }^{1}$

\begin{tabular}{llcccc}
\hline Stratum & Treatment $^{2}$ & Total & Failed & Censored & Censored, \% \\
\hline 1 & Placebo & 42 & 29 & 13 & 31.0 \\
2 & CR & 42 & 17 & 25 & 59.5 \\
Total & & 84 & 46 & 38 & 45.2 \\
\hline
\end{tabular}

${ }^{1}$ Censored calves remained healthy at $15 \mathrm{~d}$, and failed calves were diagnosed with a BRD bout within $14 \mathrm{~d}$ following intervention.

${ }^{2}$ Placebo $=125 \mathrm{~g}$ of placebo milk replacer (Cows Match, Land O'Lakes Inc.) in $1 \mathrm{~L}$ of water for $3 \mathrm{~d}$; CR $=125$ $\mathrm{g}$ of colostrum replacer (Premolac Plus, Zinpro) in $1 \mathrm{~L}$ of water for $3 \mathrm{~d}$. 
Table 2. Proportion of calves with a diarrhea bout after triggering an alarm on an automated feeder for negative deviations in milk intake or drinking speed $14 \mathrm{~d}$ following intervention by a treatment ${ }^{1}$

\begin{tabular}{llcccc}
\hline Stratum & Treatment $^{2}$ & Total & Failed & Censored & Censored, \% \\
\hline 1 & Placebo & 42 & 27 & 15 & 35.7 \\
2 & Colostrum replacer & 42 & 22 & 20 & 47.6 \\
Total & & 84 & 49 & 35 & 41.7 \\
\hline
\end{tabular}

${ }^{1}$ Censored calves remained healthy at $15 \mathrm{~d}$, and failed calves were diagnosed with a diarrhea bout within $14 \mathrm{~d}$ following intervention.

${ }^{2} \mathrm{Placebo}=125 \mathrm{~g}$ of placebo milk replacer (Cows Match, Land O'Lakes Inc.) in $1 \mathrm{~L}$ of water for $3 \mathrm{~d}$; $\mathrm{CR}=125$ $\mathrm{g}$ of colostrum replacer (Premolac Plus, Zinpro) in $1 \mathrm{~L}$ of water for $3 \mathrm{~d}$.

2020), and negatively affects ADG (Cramer and Ollivett, 2019) and future milk production (Dunn et al., 2018).

There was a preventative benefit of reducing the odds of BRD in calves treated with CR. Although we fed our calves for a short duration, our results agree with the literature that fed bovine colostrum for an extended period of several days. For example, colostrum as a nutraceutical decreased the likelihood and duration of respiratory disease in calves (Chamorro et al., 2017), and ameliorated duration of respiratory infection in juvenile racehorses (Fenger et al., 2016). Specifically in calves, research has shown feeding 150 $\mathrm{g} / \mathrm{d}$ colostrum to younger calves from $\mathrm{d} 0$ to $14 \mathrm{~d}$ of age reduced the likelihood of BRD before weaning (Chamorro et al., 2017). Moreover, a more recent, long-term study observed that extended feeding of colostrum for $21 \mathrm{~d}$ reduced BRD risk for the first year of life, and increased first lactation milk production (Armengol and Fraile, 2020). However, a recent study that partially replaced the milk diet with colostrum from birth until $14 \mathrm{~d}$ (doses included 0,350 , or $700 \mathrm{~g} / \mathrm{d}$ ), found only a tendency for BRD to be lower in calves (Kargar et al., 2020). We suspect Kargar et al., (2020) only found a tendency due to a low observed prevalence of BRD in their population of calves. In general, our results agree with the literature in calves and in other species that colostrum may reduce the risk of respiratory ailments. However, in this study, we did not evaluate the effect of colostrum replacer on the severity of lobar consolidation as we were not powered for magnitude effects. Future research should determine which component in colostrum is responsible for lowering BRD risk, and the effect of CR on the severity of lobar consolidation in calves.

Although the intervention of $\mathrm{CR}$ did not reduce the odds of diarrhea in our calves, preventative feeding of extended colostrum to calves during the first $14 \mathrm{~d}$ of life has been found to reduce the risk of diarrhea (Chamorro et al., 2017; Kargar et al., 2020). Specifically, colostrum fed for $14 \mathrm{~d}$ reduced odds of diarrhea, number of days sick with diarrhea, and number of antibiotic treatment days received compared with controls (Berge et al., 2009). Similarly, feeding $750 \mathrm{~mL}$ of lipolyzed bovine colostrum fed at $24 \mathrm{~h}$ of life reduced incidence of diarrhea in calves, although this was not seen in older calves at 48 or $72 \mathrm{~h}$ of life (Dezfouli et al., 2007). Moreover, others found that preventative feeding with colostrum for $21 \mathrm{~d}$ reduced the likelihood of diarrhea for the first $180 \mathrm{~d}$ of life (Armengol and Fraile, 2020). Our results likely differed from other studies in not affecting diarrhea likelihood because we did not feed $\mathrm{CR}$ for a long duration. Instead, we fed our calves one dose of CR (containing $150 \mathrm{~g}$ of $\mathrm{IgG}$ ) at a shorter interval and our calves were much older (i.e., a month old at the time of intervention). Calves are most at risk for diarrhea from birth until approximately $14 \mathrm{~d}$ of age, when passive immunity provided from colostrum is low (Cortese, 2009), or until $21 \mathrm{~d}$ of age when innate immunity is naive against endemic pathogens such as protozoans (as reviewed by Cho and Yoon, 2014). Because we chose to provide the AMF a 12-d acclimation period for an algorithm to establish an average, it is possible we missed the high-risk period for diarrhea in our calves. Future research should determine if younger calves receiving an AMF-based colostrum intervention would lower the risk of diarrhea.

We did not observe an effect of CR on ADG in this study. For this study, the CR and milk replacer offered had very similar levels of gross energy. However, our findings disagreed with the limited literature about extended colostrum feeding to calves and performance. Research has shown that extended feeding of colostrum by partially replacing the milk fed diet for $14 \mathrm{~d}$ with either 0,350 , or $700 \mathrm{~g} / \mathrm{d}$ colostrum can improve performance in calves postweaning (Kargar et al., 2020). Similarly feeding calves by partially replacing the milk meal with colostrum $(2.3 \mathrm{~L})$ for the first $21 \mathrm{~d}$ of life, resulted in greater first lactation body weights, though early life weights were not recorded (Armengol and Fraile, 2020). Finally, in parallel, work that investigated the effects of lactoferrin, a component of colostrum, did not observe an effect of lactoferrin on performance in calves (English et al., 2007; Pempek et al., 2018). 
Thus, the literature suggests that calves fed colostrum for extended periods had positive average daily gain effects. Our results may have disagreed with these studies because we fed a much lower dose of colostrum for a shorter duration (i.e., $125 \mathrm{~g}$ for $3 \mathrm{~d}$ ). Alternatively, it is possible that we did not find an effect of $\mathrm{CR}$ on ADG because the placebo calves received milk replacer that contained similar and even slightly more gross energy than the CR, a study design difference from others who partially replaced the milk diet, or compared with a negative control. Thus, in our study, ADG was not affected in CR fed calves when the placebo calves received a high energy milk replacer. Future research should investigate if $\mathrm{CR}$ at this dosage compared with a negative control positively affects ADG in calves.

We acknowledge that one of the limitations of our study was that our researchers were not blind to treatment assignments after the colostrum or placebo feedings. Similarly, the AMF alarm used in this trial has not been previously used as a proxy for intervention in dairy calves. We encourage future work to investigate the utilization of different alarms as proxy for treatments in dairy calves. Nonetheless, preventing BRD by intervening with $\mathrm{CR}$ when an AMF alarm is detected may improve the welfare of calves.

In summary, we observed that colostrum supplementation during a negative deviation in average milk intake and drinking speed resulted in reduced likelihood for the calf to develop BRD in the following 14 $\mathrm{d}$, but there was no effect on development of diarrhea or performance over this period. Although colostrum in our study did not reduce the likelihood of diarrhea, our calves triggered alarms at a month of age and were past the at-risk period for pathogenic diarrhea. Although we observed an effect of $\mathrm{CR}$ to ameliorate and reduce the likelihood of BRD, future research should attempt to disentangle and identify the influence of each factor present in colostrum such as the IgG, lactoferrin or another component that is actually responsible for improved respiratory health in older calves. Similarly, a lack of effect of colostrum on performance was likely a result of a high plane of nutrition being offered to the calves. Alternatively, it is possible that ADG was compromised by sick calves on this study due to antibiotic intervention. Colostrum many ameliorate BRD in preweaning calves, and the use of an AMF negative deviation in feed intake may be a potential intervention tool.

\section{CONCLUSIONS}

Colostrum offered as a nutraceutical at $125 \mathrm{~g} / \mathrm{d}$ for $3 \mathrm{~d}(50 \mathrm{~g}$ of $\mathrm{IgG} / \mathrm{d})$ may ameliorate BRD bouts, and reduce the odds of $\mathrm{BRD}$ when offered to calves who change their feeding behavior. However, there was no effect of colostrum treatment on amelioration of diarrhea, which may be related to the older age at which calves were treated (i.e., at 1 mo. of age). There also was no effect of colostrum treatment on performance, perhaps because calves receiving the placebo milk replacer treatment received a similar level of gross energy. This study offers early evidence that colostrum intervention can improve calf health. Future work is required to determine which components in colostrum are most effective, and whether colostrum intervention at younger ages may also reduce diarrhea risk.

\section{ACKNOWLEDGMENTS}

The research for this study was funded by a USDA NIFA Hatch Grant Project KY007100 at the University of Kentucky. The authors thank Zinpro Corporation for their donation of CR for this study. The authors also thank graduate students and visiting intern students who assisted this trial while attending the University of Kentucky: Megan Woodrum Setser, Charlotte Pertuisel, Giulia Gobbo Rodrigues, Anna Hawkins, Gustavo Mazon and all other staff and students for assistance with the trial. The authors do not claim any conflict of interest.

\section{REFERENCES}

Aghakeshmiri, F., M. Azizzadeh, N. Farzaneh, and M. Gorjidooz. 2017. Effects of neonatal diarrhea and other conditions on subsequent productive and reproductive performance of heifer calves. Vet. Res. Commun. 41:107-112. https://doi.org/10.1007/s11259 -017-9678-9.

Alexieva, B., T. Markova, and E. Nikolova. 2011. Bovine colostrum: The promising nutraceutical. Czech J. Food Sci. 22:73-79. https:/ /doi.org/10.17221/3409-CJFS.

Armengol, R., and L. Fraile. 2020. Feeding calves with pasteurized colostrum and milk has a positive long-term effect on their productive performance. Animals (Basel) 10:1494. https://doi.org/10 $.3390 /$ ani10091494.

Bagwe, S., L. J. P. Tharappel, G. Kaur, and H. S. Buttar. 2015. Bovine colostrum: An emerging nutraceutical. J. Complement. Integr. Med. 12:175-185. https://doi.org/10.1515/jcim-2014-0039.

Berge, A. C. B., T. E. Besser, D. A. Moore, and W. M. Sischo. 2009. Evaluation of the effects of oral colostrum supplementation during the first fourteen days on the health and performance of preweaned calves. J. Dairy Sci. 92:286-295. https://doi.org/10.3168/ jds.2008-1433.

Boudry, C., A. Buldgen, D. Portetelle, A. Collard, A. Théwis, and J. P. Dehoux. 2007. Effects of oral supplementation with bovine colostrum on the immune system of weaned piglets. Res. Vet. Sci. 83:91-101. https://doi.org/10.1016/j.rvsc.2006.11.003.

Buczinski, S., M. E. Borris, and J. Dubuc. 2018. Herd-level prevalence of the ultrasonographic lung lesions associated with bovine respiratory disease and related environmental risk factors. J. Dairy Sci. 101:2423-2432. https://doi.org/10.3168/jds.2017-13459.

Cantor, M. C., A. L. Stanton, D. K. Combs, and J. H. C. Costa. 2019. Effect of milk feeding strategy and lactic acid probiotics on growth and behavior of dairy calves fed using an automated feeding system. J. Anim. Sci. 97:1052-1065. https://doi.org/10.1093/ jas/skz034. 
Chamorro, M., N. Cernicchiaro, and D. M. Haines. 2017. Evaluation of the effects of colostrum replacer supplementation of the milk replacer ration on the occurrence of disease, antibiotic therapy, and performance of pre-weaned dairy calves. J. Dairy Sci. 100:1378 1387. https://doi.org/10.3168/jds.2016-11652.

Cho, Y. I., and K.-J. Yoon. 2014. An overview of calf diarrhea - infectious etiology, diagnosis, and intervention. J. Vet. Sci. 15:1-17. https://doi.org/10.4142/jvs.2014.15.1.1.

Cortese, V. S. 2009. Neonatal immunology. Vet. Clin. North Am. Food Anim. Pract. 25:221-227. https://doi.org/10.1016/j.cvfa.2008.10 .003 .

Cramer, M. C., and T. L. Ollivett. 2019. Growth of preweaned, grouphoused dairy calves diagnosed with respiratory disease using clinical respiratory scoring and thoracic ultrasound-A cohort study. J. Dairy Sci. 102:4322-4331. https://doi.org/10.3168/jds.2018-15420.

Deelen, S. M., T. L. Ollivett, D. M. Haines, and K. E. Leslie. 2014. Evaluation of a Brix refractometer to estimate serum immunoglobulin G concentration in neonatal dairy calves. J. Dairy Sci. 97:3838-3844. https://doi.org/10.3168/jds.2014-7939.

Dezfouli, M., F. Rezazadeh, M. Rabbani, S. Zahraai, and H. Seifi. 2007. Efficacy of dried colostrum powders in the prevention of diarrhea in neonatal Holstein calves. Comp. Clin. Path. 16:127-130. https://doi.org/10.1007/s00580-006-0652-0.

Dubrovsky, S. A., A. L. Van Eenennaam, S. S. Aly, B. M. Karle, P. V. Rossitto, M. W. Overton, T. W. Lehenbauer, and J. G. Fadel. 2020. Preweaning cost of bovine respiratory disease (BRD) and cost-benefit of implementation of preventative measures in calves on California dairies: The BRD 10K study. J. Dairy Sci. 103:15831597. https://doi.org/10.3168/jds.2018-15501.

Dubrovsky, S. A., A. L. Van Eenennaam, B. M. Karle, P. V. Rossitto, T. W. Lehenbauer, and S. S. Aly. 2019. Bovine respiratory disease (BRD) cause-specific and overall mortality in preweaned calves on California dairies: The BRD 10K study. J. Dairy Sci. 102:73207328. https://doi.org/10.3168/jds.2018-15463.

Dunn, T. R., T. L. Ollivett, D. L. Renaud, K. E. Leslie, S. J. Leblanc, T. F. Duffield, and D. F. Kelton. 2018. The effect of lung consolidation, as determined by ultrasonography, on first-lactation milk production in Holstein dairy calves. J. Dairy Sci. 101:5404-5410. https://doi.org/10.3168/jds.2017-13870.

English, E. A., B. A. Hopkins, J. S. Stroud, S. Davidson, G. Smith, C. Brownie, and L. W. Whitlow. 2007. Lactoferrin supplementation to Holstein calves during the preweaning and postweaning phases. J. Dairy Sci. 90:5276-5281. https://doi.org/10.3168/jds .2007-0361.

Fenger, C. K., T. Tobin, P. J. Casey, E. A. Roualdes, J. L. Langemeier, R. Cowles, and D. M. Haines. 2016. Enhanced bovine colostrum supplementation shortens the duration of respiratory disease in thoroughbred yearlings. J. Equine Vet. Sci. 42:77-81. https://doi .org/10.1016/j.jevs.2016.03.012.

Giansanti, F., G. Panella, L. Leboffe, and G. Antonini. 2016. Lactoferrin from milk: Nutraceutical and pharmacological properties. Pharmaceuticals (Basel) 9:61. https://doi.org/10.3390/ph9040061.

Goodell, G. M., J. Campbell, L. Hoejvang-Nielsen, W. Stansen, and P. D. Constable. 2012. An alkalinizing oral rehydration solution containing lecithin-coated citrus fiber is superior to a nonalkalinizing solution in treating 360 calves with naturally acquired diarrhea. J. Dairy Sci. 95:6677-6686. https://doi.org/10.3168/jds.2012-5605.

Hawkins, A., K. Burdine, D. Amaral-Phillips, and J. H. C. Costa. 2019. An economic analysis of the costs associated with preweaning management strategies for dairy heifers. Animals (Basel) 9:471. https://doi.org/10.3390/ani9070471.

Kargar, S., M. Roshan, S. M. Ghoreishi, A. Akhlaghi, M. Kanani, A. R. Abedi Shams-Abadi, and M. H. Ghaffari. 2020. Extended colostrum feeding for 2 weeks improves growth performance and reduces the susceptibility to diarrhea and pneumonia in neonatal Holstein dairy calves. J. Dairy Sci. 103:8130-8142. https://doi .org/10.3168/jds.2020-18355.
Knauer, W. A., S. M. Godden, A. Dietrich, and R. E. James. 2017. The association between daily average feeding behaviors and morbidity in automatically fed group-housed preweaned dairy calves. J. Dairy Sci. 100:5642-5652. https://doi.org/10.3168/jds.2016-12372.

Lee, A., M. C. F. Pontin, E. Kosmerl, R. Jimenez-Flores, D. B. Moretti, and O. Ziouzenkova. 2019. Assessment of adipogenic, antioxidant, and anti-inflammatory properties of whole and whey bovine colostrum. J. Dairy Sci. 102:8614-8621. https://doi.org/10.3168/ jds.2019-16509.

McGuirk, S. M., and S. F. Peek. 2014. Timely diagnosis of dairy calf respiratory disease using a standardized scoring system. Anim. Health Res. Rev. 15:145-147. https://doi.org/10.1017/ S1466252314000267.

Menchetti, L., G. Curone, I. Filipescu, O. Barbato, L. Leonardi, G. Guelfi, G. Traina, P. Casagrande-Proietti, F. Riva, A. Casano, F. Piro, D. Vigo, A. Quattrone, and G. Brecchia. 2020. The prophylactic use of bovine colostrum in a murine model of TNBSinduced colitis. Animals (Basel) 10:492. https://doi.org/10.3390/ ani10030492.

Nasri, H., A. Baradaran, H. Shirzad, and M. Rafieian-Kopaei. 2014. New concepts in nutraceuticals as alternative for pharmaceuticals. Int. J. Prev. Med. 5:1487-1499.

Pempek, J. A., E. Holder, K. L. Proudfoot, M. Masterson, and G. Habing. 2018. Short communication: Investigation of antibiotic alternatives to improve health and growth of veal calves. J. Dairy Sci. 101:4473-4478. https://doi.org/10.3168/jds.2017-14055.

Placzek, M., I. Christoph-Schulz, and K. Barth. 2020. Public attitude towards cow-calf separation and other common practices of calf rearing in dairy farming - A review. Org. Agric. https://doi.org/ 10.1007/s13165-020-00321-3.

Renaud, D. L., L. Buss, J. N. Wilms, and M. A. Steele. 2020. Technical note: Is fecal consistency scoring an accurate measure of fecal dry matter in dairy calves? J. Dairy Sci. 103:10709-10714. https://doi .org/10.3168/jds.2020-18907.

Rosenberger, K., J. H. C. Costa, H. W. Neave, M. A. G. von Keyserlingk, and D. M. Weary. 2017. The effect of milk allowance on behavior and weight gains in dairy calves. J. Dairy Sci. 100:504-512. https://doi.org/10.3168/jds.2016-11195.

Satyaraj, E., A. Reynolds, R. Pelker, J. Labuda, P. Zhang, and P. Sun. 2013. Supplementation of diets with bovine colostrum influences immune function in dogs. Br. J. Nutr. 110:2216-2221. https://doi .org/10.1017/S000711451300175X.

Sutherland, M. A., G. L. Lowe, F. J. Huddart, J. R. Waas, and M. Stewart. 2018. Measurement of dairy calf behavior prior to onset of clinical disease and in response to disbudding using automated calf feeders and accelerometers. J. Dairy Sci. 101:8208-8216. https: //doi.org/10.3168/jds.2017-14207.

Teixeira, A. G. V., J. A. A. McArt, and R. C. Bicalho. 2017. Thoracic ultrasound assessment of lung consolidation at weaning in Holstein dairy heifers: Reproductive performance and survival. J. Dairy Sci. 100:2985-2991. https://doi.org/10.3168/jds.2016-12016.

USDA. 2018. Health and Management Practices on U.S. Dairy Operations, Dairy 2014. USDA-APHIS-VS-CEAH-NAHMS.

Woodrum Setser, M. M., M. C. Cantor, and J. H. C. Costa. 2020. A comprehensive evaluation of microchips to measure temperature in dairy calves. J. Dairy Sci. 103:9290-9300. https://doi.org/10 $.3168 /$ jds.2019-17999.

\section{ORCIDS}

M. C. Cantor (ํ) https://orcid.org/0000-0002-4963-064X

D. L. Renaud ๑ https://orcid.org/0000-0002-3439-3987

J. H. C. Costa $\odot$ https://orcid.org/0000-0001-9311-4741 